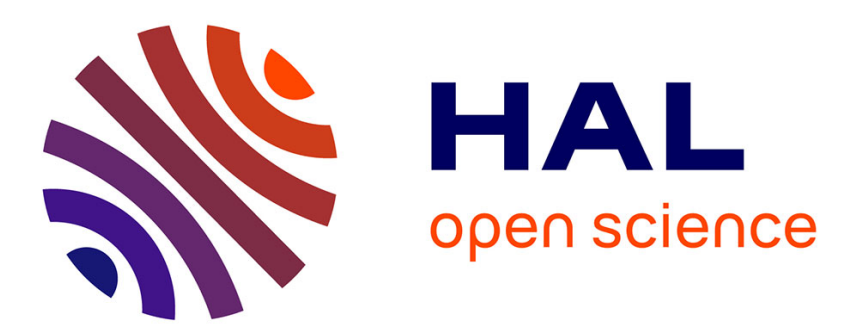

\title{
A continuum damage model applied to high temperature fatigue lifetime prediction of a martensitic tool steel
}

\author{
Vincent Velay, Gérard Bernhart, Denis Delagnes, Luc Penazzi
}

\section{To cite this version:}

Vincent Velay, Gérard Bernhart, Denis Delagnes, Luc Penazzi. A continuum damage model applied to high temperature fatigue lifetime prediction of a martensitic tool steel. Fatigue and Fracture of Engineering Materials and Structures, 2005, 28 (11), pp.1009-1023. 10.1111/j.1460-2695.2005.00939.x . hal-01384443

\section{HAL Id: hal-01384443 \\ https://hal.science/hal-01384443}

Submitted on 19 Oct 2016

HAL is a multi-disciplinary open access archive for the deposit and dissemination of scientific research documents, whether they are published or not. The documents may come from teaching and research institutions in France or abroad, or from public or private research centers.
L'archive ouverte pluridisciplinaire HAL, est destinée au dépôt et à la diffusion de documents scientifiques de niveau recherche, publiés ou non, émanant des établissements d'enseignement et de recherche français ou étrangers, des laboratoires publics ou privés. 


\title{
A continuum damage model applied to high temperature fa- tigue lifetime prediction of a martensitic tool steel
}

\author{
V.VELAY ${ }^{1}$, G. BERNHART, D. DELAGNES and L. PENAZZI
}

Research Centre on Tools, Materials and Processes (CROMeP) - Ecole des Mines d'Albi-Carmaux-Campus Jarlard 81013 ALBI cedex 09, France

ABSTRACT High temperature operational conditions of hot work tool steels induce several thermomechanical loads. Depending on the processes, (i.e: forging, die casting or extrusion), stress, strain, strain rate and temperature levels applied on the material are nevertheless very different. Thus, lifetime prediction models need to be able to take into account a broad range of working conditions. In this paper, a non-isothermal continuum damage model is identified for a widely used hot work tool steel AISI H11 (X38CrMoV5) with a nominal hardness of $47 \mathrm{HRc}$. This investigation is based on an extensive high temperature low cycle fatigue data base performed under strain rate controlled conditions with and without dwell times in the temperature range $300^{\circ} \mathrm{C}-600^{\circ} \mathrm{C}$. As analysis of experimental results does not reveal significant time dependent damage mechanisms, only a fatigue damage component was activated in the model formulation. After normalization, all fatigue results are defined on a master Woehler curve defined by a non-linear damage model, which allows the parameter identification. Last, a validation stage of the model is performed from thermomechanical fatigue tests.

Keywords continuum damage mechanics; tempered martensitic steels; Woehler curve; fatigue life prediction; high temperature fatigue

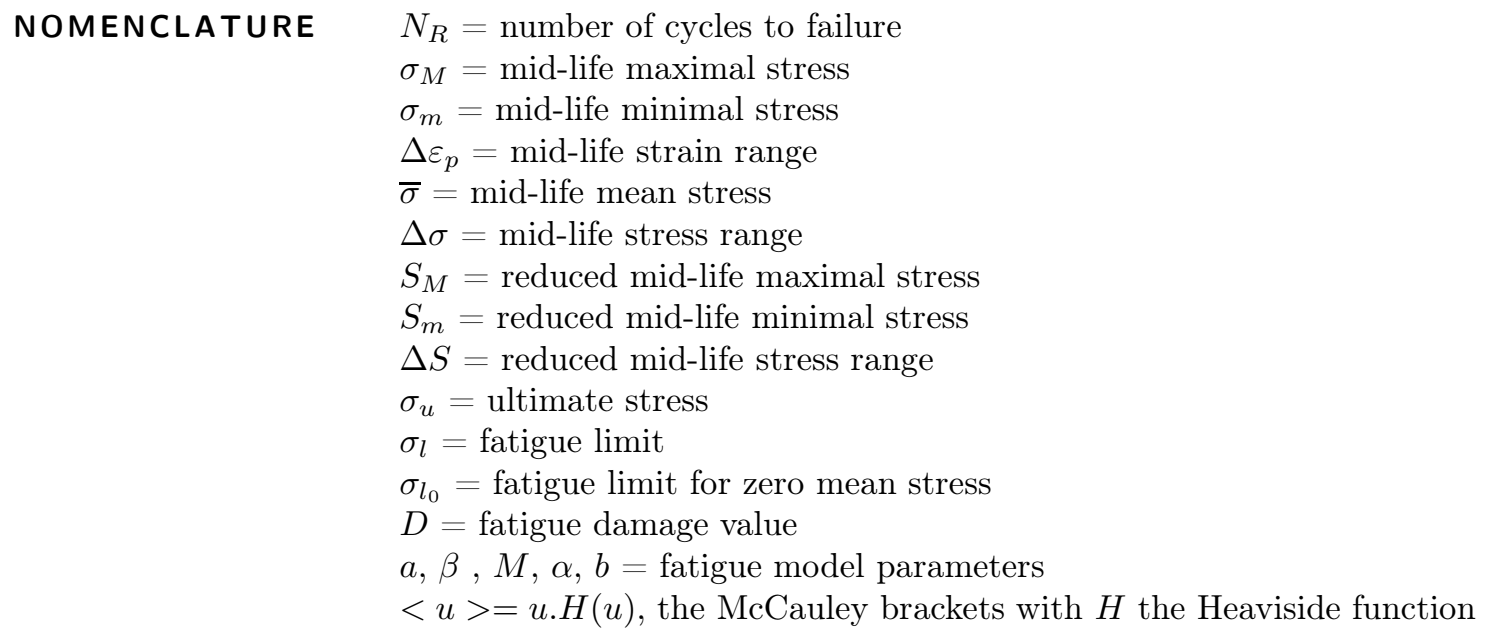

\footnotetext{
${ }^{1}$ Correspondence: V. Velay. E-mail: vincent.velay@enstimac.fr
} 


\section{INTRODUCTION}

Hot work tool steels undergo very critical thermo-mechanical loads that are usually very hard to evaluate from an experimental point of view and whose levels strongly depend on the location on the structure. Numerical simulation seems to be adequate to reach this information in order to optimize the tool design and to improve their lifetime. For that purpose, several preliminary stages are necessary. First of all, a cyclic elasto-viscoplastic behavior model has to be identified in order to provide stress-strain curves under thermo-mechanical conditions very useful for the lifetime models. Then, finite element implementation allows to evaluate stress and strain levels in the tools during the forming processes. Several papers were published related to the behavior modeling of martensitic steel. ${ }^{1-4}$ These models were formulated in agreement with the irreversible processes of the thermodynamic. $^{5-8}$ Thus, the locations on the tool very sensitive to damage and the number of cycles to failure may be assessed with a lifetime model. This paper deals with the identification process of a non-isothermal continuum damage model applied to the AISI H11 tool steel.

For several tenth years, a lot of prediction models have been developed. A very complete review of the prediction theories can be found in the paper of Fatemi and Yang. ${ }^{9}$ The objective of this work is not to perform a historical review of the fatigue damage models. For this reason, only a very brief presentation of some approaches will be made here, with the risk to omit some important works that have contributed to the development of this research area. Literature provides different approaches which can be formulated in terms of strain, stress or energy.

\section{Strain formulated approach}

Manson-Coffin and Basquin formulations ${ }^{10,11}$ are the most commonly used.

These approaches are able to take into account multiaxial loadings including equivalent plastic strain amplitude. However, this formulation is usually not suitable to high temperature fatigue where time dependent damage occurs.

Different additional effects are not considered as the mean stress influence and the complex thermomechanical loadings where temperature evolves within the mechanical cycle. Moreover, the very large number of cycles to failure are not well assessed by this way. Manson-Coffin and
Basquin laws have provided successful results related to isothermal fatigue tests performed on AISI L6 ${ }^{1}$ and AISI H11 ${ }^{12,13}$ steels.

Different damage functions can be used with the previous models as those of Smith, Watson, Topper and Bergmann ${ }^{14}$ that introduce maximal stress concept. They consider the mean stress effect that may have a great impact on the fatigue lifetime. Strain energy criteria $^{14,15}$ (Hänsel or Glinka criteria) related to MansonCoffin relations allows to predict fatigue lifetime under multiaxial configuration.

Another formulation commonly used was proposed by Halford and Manson ${ }^{16,17}$ and called Strain Range Partitioning method. It consists in partitioning the cycle in four characteristic cycles related to four different kinds of damage as compressive and tensile fatigue and creep damages.

This approach allows to define the time dependent and time independent damages. It can be modified in order to take into account the mean stress effect. ${ }^{18}$ However, the lifetime assessments provided by this approach were usually not in a good agreement with experimental tests. $^{19}$

\section{Energetic approaches}

The most important energetic approaches are those developed by Ostergren ${ }^{20}$ and Skelton. The first one considers tensile hysteresis energy assuming that crack initiation only occurs in a tensile loading ${ }^{20}$ beyond a threshold stress.

As the strain formulated approaches, time effect can be introduced in the formulation. ${ }^{20}$

The Skelton's approach considers the cyclic softening or hardening saturation and evaluates a maximal cumulative energy which defines the crack initiation. $^{21,22}$ This approach can assess the number of cycles to failure from maximal energy calculation.

Among all the previous approaches, one of the difficulties remains the reference cycle selection when no cyclic stabilization occurs (cyclic hardening or softening).

Several energetic criteria were defined. One of them ${ }^{21}$ considered a fatigue damage linear cumulative rule applied from an energetic point of view. It considers the total plastic work evolution $^{22}$ and allows to define a maximal cumulative energy. Energy summation can be calculated considering the end of the cyclic softening or hardening phases. Dwell time effects within cycles can be introduced. ${ }^{21}$ Skelton et al. have also developed an energetic approach based on 
the fracture mechanism concept. ${ }^{23}$ It considers a dissipated energy per cycle as a damage indicator associated with a failure criterion. ${ }^{24}$ This approach was successfully applied in the automotive industry. ${ }^{24-28}$

\section{Stress formulated approach}

This approach is based on continuum damage mechanic, it describes the evolution between the virgin state and the initiation state of the macroscopic crack. Thus, the ultimate damage stage is characterized by the fracture of the representative volume element. ${ }^{17}$ Two kinds of damages may occur:

- transgranular fatigue damage for high frequency fatigue tests

- intergranular creep damage which may be very important for low frequency fatigue tests at high temperature (high creep component).

This paper presents a detailed description of this approach applied to AISI H11 steel. This method takes into account time dependent effects and fatigue damage interactions. It allows to consider the non linearity of the damage curves and the cumulative effect of both damage components. ${ }^{19,29-32}$ This phenomenological model was successfully applied in a multiaxial framework. ${ }^{33}$ Moreover, it exhibits a damage evolution which can be considered different in a tensile and compressive test. ${ }^{17}$ Influences of temperature evolution within cycles and material ageing on the lifetime can also be considered. ${ }^{34}$ Thus, the model capabilities can be extended to thermomechanical fatigue and high cycle fatigue. ${ }^{35,36}$ Some investigations were also performed in order to understand crack initiation phenomena. Indeed, Cailletaud and Levaillant $^{37}$ have divided the fatigue damage component into two stages as a crack micro initiation and a crack micro propagation. Creep interacts only with the crack micro propagation. In a similar way, the damage due to the environment (oxide) can be taken into account. ${ }^{38}$ Such an approach can also be formulated in terms of strain. $^{39}$

\section{MATERIAL AND TESTING}

The continuous fatigue softening from the first cycle until rupture is typical of the AISI H11 martensitic steel. If the stress range is plotted versus the number of cycles (figure 1) or the cumulative plastic strain, this softening can be divided into three successive stages. Indeed, the strong softening stage occurring during the first hundred of cycles is followed by a pseudostability one (weak softening) during the major part of the lifetime. At the end, crack propagation occurs, defined by a fast decrease of the stress range before rupture. ${ }^{1}$

The chemical composition of the steel is presented in table 1 , and the heat treatment operations are described in table 2 . It consists in austenitizing, quenching and two tempering operations which confer to the material a nominal Rockwell hardness of $47 \mathrm{HRc}$.

Low cycle fatigue tests were carried out with a SHENCK HYDROPULS servo hydraulic testing machine and Testar $2 \mathrm{~S}$ controller connected to a computer. Heating was achieved with a resistive furnace (figure 2). Axial extensometer allows strain measurement adapted to high temperature fatigue tests. A more detailed description is available in a previous paper. ${ }^{12}$

\begin{tabular}{ccccccccc}
\multicolumn{8}{c}{ Table 1: } & Chemical composition of AISI H11 steel (weight \%) \\
\hline El. & $\mathrm{C}$ & $\mathrm{Ni}$ & $\mathrm{Cr}$ & $\mathrm{Mo}$ & $\mathrm{V}$ & $\mathrm{Si}$ & $\mathrm{Mn}$ & $\mathrm{Fe}$ \\
$\mathrm{H} 11$ & 0.40 & 0.20 & 5.05 & 1.25 & 0.47 & 0.92 & 0.49 & bal \\
\hline
\end{tabular}

Table 2: Heat treatments of AISI H11 stee

\begin{tabular}{cccccc}
\multicolumn{7}{c}{ Table 2: Heat treatments of AISI H11 steel } \\
\hline Steel & Austenitizing & Quenching & $1^{\text {st }}$ tempering & $2^{\text {nd }}$ tempering & Hardness \\
H11 & $990^{\circ} \mathrm{C}$ & $1 \mathrm{~h} /$ gas & $550^{\circ} \mathrm{C} / 2 \mathrm{~h}$ & $605^{\circ} \mathrm{C} / 2 \mathrm{~h}$ & $47 \mathrm{HRc}$ \\
\hline
\end{tabular}

An automatic process was implemented in order to calculate the relevant values of a cycle as total and plastic strains, stresses, cumulative plastic strain. Experimental data used to iden- tify the lifetime model, include 46 total strain controlled low cycle fatigue tests for temperature levels between $300^{\circ} \mathrm{C}$ and $600^{\circ} \mathrm{C}$. Some of them were performed at a very low frequency 


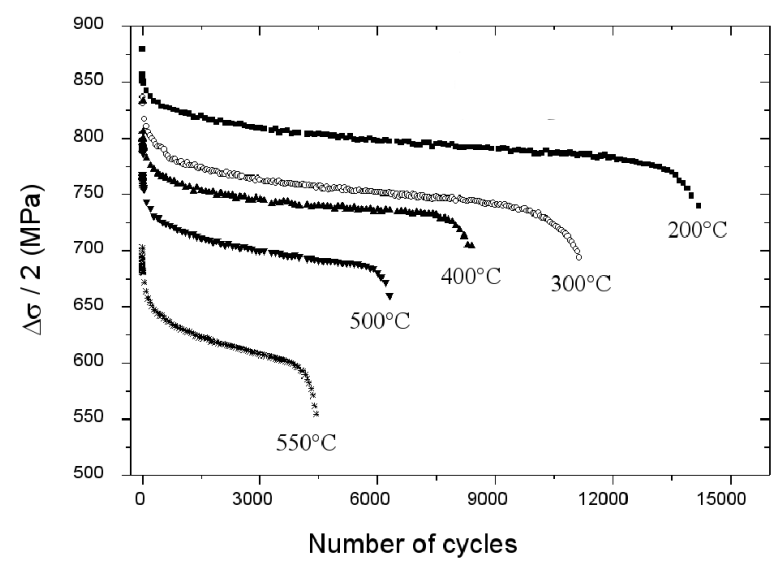

Fig. 1: Stress amplitude versus number of cycles for different temperature levels ${ }^{12}$

$\left(\dot{\varepsilon}=10^{-3} s^{-1}\right)$ including tensile and compressive dwell times $(60 \text { and } 90 \mathrm{~s})^{12,40}$ as described in figure 3. High frequency low cycle tests were considered for the other tests with strain rates about $\dot{\varepsilon}=10^{-2} s^{-1} \cdot{ }^{12}$ Thus, test conditions investigated include a very broad temperature and strain rate range and contribute to give an important validity domain for the model.

\section{FATIGUE TEST RESULTS}

\section{Cyclic softening}

Test conditions as temperature, frequency, strain range can affect lifetime.

For the same strain ranges, figure 1 shows that an increase of the temperature implies a decrease of stress level, a more important cyclic softening intensity and shorter lifetimes.

Cyclic softening intensity increases and lifetime decreases when higher strain levels are considered whereas cumulative plastic strain decreases as shown in figure 4 . For very low loadings, the strong softening which normally occurs during the first hundred of cycles completely vanishes (Figures 4-5).

Dwell times and strain rates have a signifi-

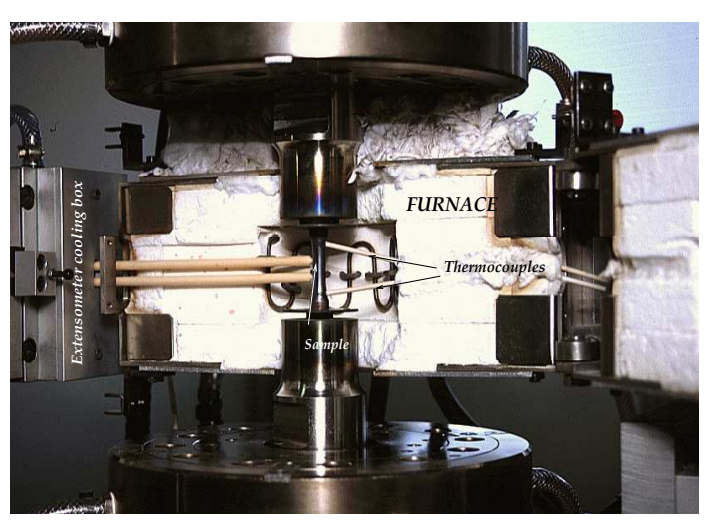

Fig. 2: Fatigue testing facility

cant effect on lifetimes. At high temperature, the more strain rate is low, the more cyclic softening intensity is important (figures 6 and 7). Moreover, lifetime is greatly reduced by a decrease of the test frequency. Dwell times also introduce time dependent effects and thus, affect the lifetime. Compressive dwell times appear to be the most damaging loadings and lead to the shorter lifetimes.

Experimental Woehler curves are presented in figure 8 for different temperature levels. For similar test conditions (temperature and strain amplitude), it can be concluded that lifetime decreases when strain rate decreases; stress levels decrease when test temperature increases. However, test conditions have low effect on the slopes of the Woehler curves.

\section{Lifetime}

Table 3 provides the mean values of the Young modulus. For each test temperature, a scattering about $5 \%$ is found in the calculation of Young moduli. All the experimental fatigue tests including the number of cycles to failure $N_{R}$, the maximal and minimal stress and the strain range at mid-life, are given in tables 4 and 5 .

Table 3: Evolution of the Young modulus with the test temperature

\begin{tabular}{|c|cccccc|}
\hline Temperature [Celsius] & 300 & 500 & 520 & 550 & 560 & 600 \\
\hline Young modulus [MPa] & 191000 & 176500 & 171000 & 165000 & 164000 & 147000 \\
\hline
\end{tabular}




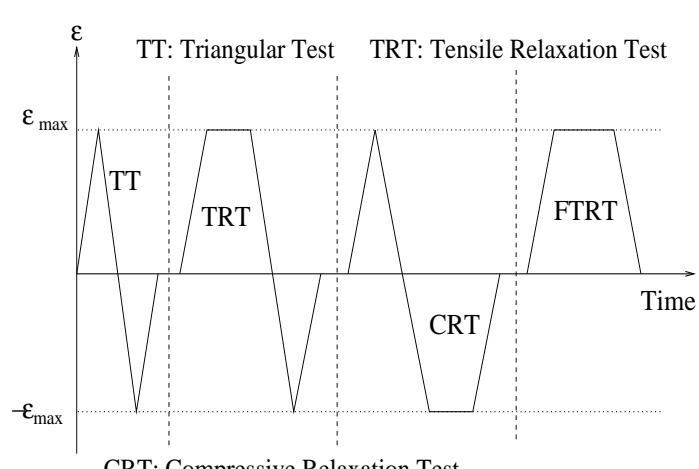

CRT: Compressive Relaxation Test

FTRT: Fully Tensile Relaxation Test

Fig. 3: Description of the cyclic loadings

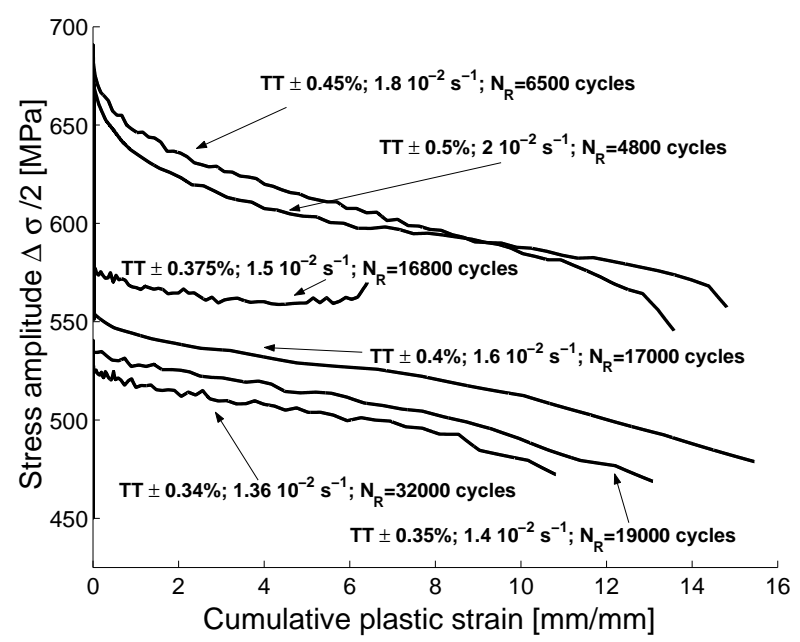

Fig. 5: Stress amplitude versus cumulative plastic strain $\left(\mathrm{T}=600^{\circ} \mathrm{C}\right)$

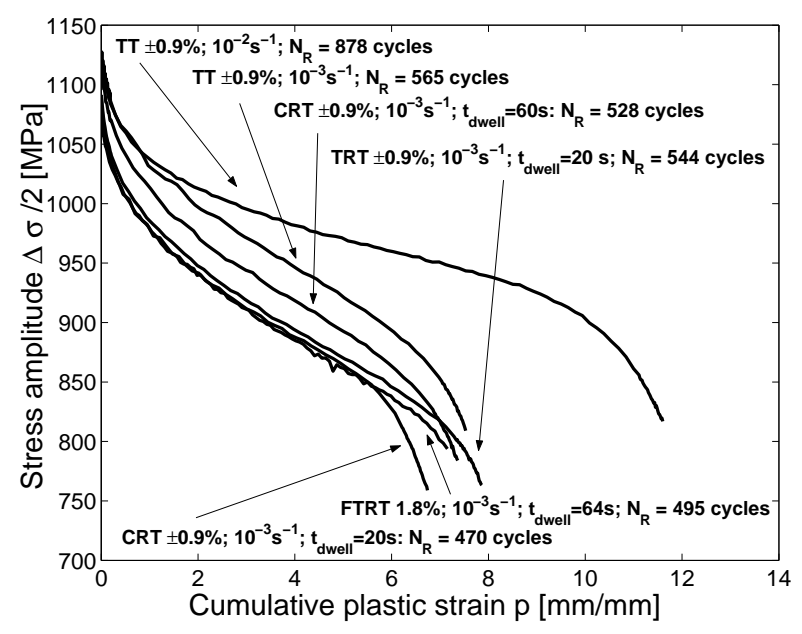

Fig. 7: Dwell times and strain rate effects on lifetime for a total strain amplitude of $1.8 \%\left(\mathrm{~T}=520^{\circ} \mathrm{C}\right)$

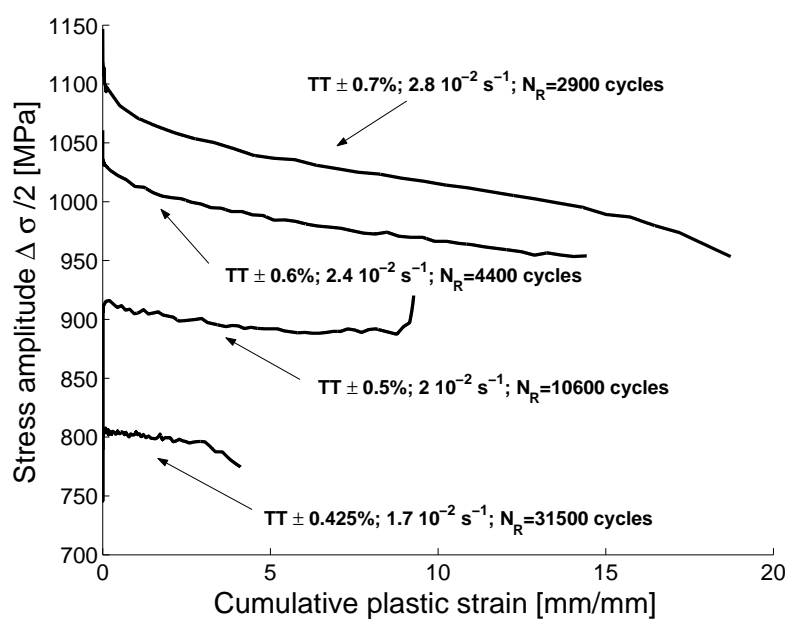

Fig. 4: Stress amplitude versus cumulative plastic strain $\left(\mathrm{T}=300^{\circ} \mathrm{C}\right)$

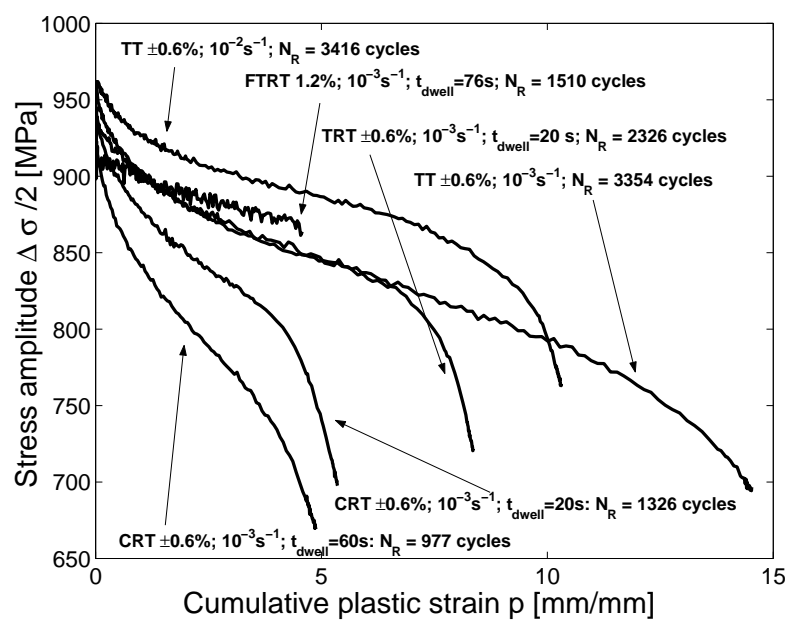

Fig. 6: Dwell times and strain rate effects on lifetime for a total strain amplitude of $1.2 \%\left(\mathrm{~T}=520^{\circ} \mathrm{C}\right)$

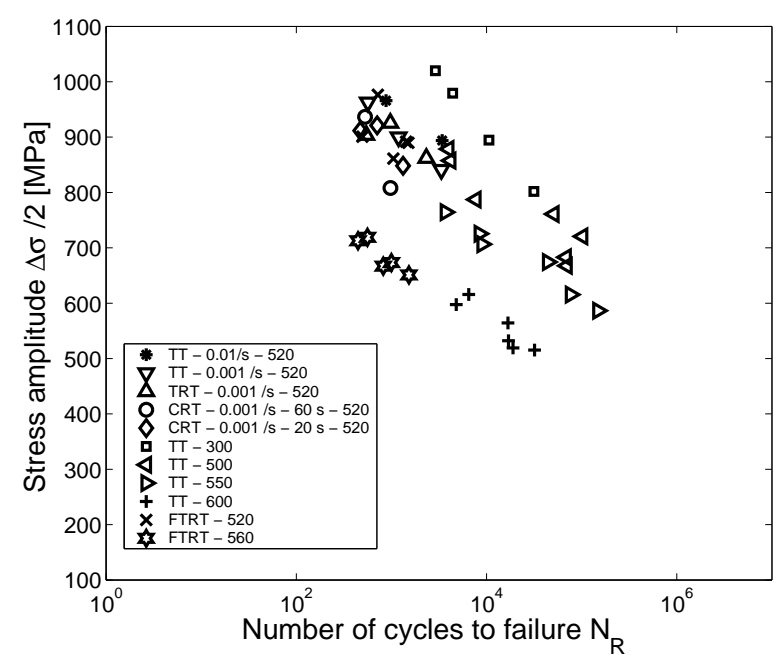

Fig. 8: Woehler curves including all the fatigue tests 
Table 4: Test conditions and results $\left(\mathrm{T}=300^{\circ} \mathrm{C}, 500^{\circ} \mathrm{C}, 520^{\circ} \mathrm{C}, 560^{\circ} \mathrm{C} \text { and } 600^{\circ} \mathrm{C}\right)^{12}$

\begin{tabular}{|c|c|c|c|c|c|c|c|c|}
\hline & Specimen & $\Delta \varepsilon[\%]$ & $\dot{\varepsilon}\left[s^{-1}\right]$ & $t_{\text {dwell }[\mathrm{s}]}$ & $N_{R}$ [cycles] & $\sigma_{m}$ & $\sigma_{M}[\mathrm{MPa}]$ & $\Delta \varepsilon_{p}[\%]$ \\
\hline \multirow{4}{*}{$\begin{array}{l}0 \\
0 \\
8 \\
\circ \\
\infty\end{array}$} & TT0425_1.7.10-2_300 & \pm 0.425 & $1.7 .10^{-2}$ & 0 & 31500 & -812 & 790 & 0.006 \\
\hline & TT05_2.10-2_300 & \pm 0.5 & $2.10^{-2}$ & 0 & 10600 & -896 & 892 & 0.046 \\
\hline & $\begin{array}{lll}\text { TT06 } & 2.4 .10-2 & 300\end{array}$ & \pm 0.6 & $2.4 .10^{-2}$ & 0 & 4400 & -1003 & 955 & 0.168 \\
\hline & TT07_2.8.10-2_300 & \pm 0.7 & $2.8 .10^{-2}$ & 0 & 2900 & -1042 & 998 & 0.325 \\
\hline \multirow{7}{*}{$\begin{array}{l}0 \\
0 \\
8 \\
10 \\
11 \\
\text { F- }\end{array}$} & TT045_1.8.10-2_500 & \pm 0.45 & $1.8 .10^{-2}$ & 0 & 68500 & -763 & 602 & 0.031 \\
\hline & $\begin{array}{lll}\text { TT045 } & 1.8 .10-2 & 500\end{array}$ & \pm 0.45 & $1.8 .10^{-2}$ & $\overline{0}$ & 70000 & -709 & 626 & 0.016 \\
\hline & TT046_1.84.10-2_500 & \pm 0.46 & $1.84 .10^{-2}$ & 0 & 102000 & -733 & 708 & 0.025 \\
\hline & TT0475_1.9.10-2_500 & \pm 0.475 & $1.910^{-2}$ & 0 & 51000 & -797 & 724 & 0.029 \\
\hline & TT05_2.10-2_500 & \pm 0.5 & $2.10^{-2}$ & 0 & 7709 & -858 & 715 & 0.037 \\
\hline & TT06_2.4.10-2_500 & \pm 0.6 & $2.4 .10^{-2}$ & 0 & 4200 & -890 & 824 & 0.125 \\
\hline & TT06_2.4.10-2_500 & \pm 0.6 & $2.4 .10^{-2}$ & 0 & 4000 & -898 & 858 & 0.131 \\
\hline \multirow{5}{*}{$\begin{array}{l}0 \\
0 \\
\stackrel{2}{0} \\
\text { iv } \\
\| \\
\text { II }\end{array}$} & F2RT1.2_10-3_76_520 & +1.2 & $10^{-3}$ & 76 & 1510 & -946 & 834 & 0.153 \\
\hline & F2RT1.35_10-3_73_520 & +1.35 & $10^{-3}$ & 76 & 1430 & -963 & 817 & 0.305 \\
\hline & F2RT1.5_10-3_70_520 & +1.5 & $10^{-3}$ & 70 & 1050 & -918 & 804 & 0.491 \\
\hline & F2RT1.8_10-3_64_520 & +1.8 & $10^{-3}$ & 64 & 495 & -945 & 856 & 0.741 \\
\hline & F2RT1.8_10-3_64_520 & +1.8 & $10^{-3}$ & 64 & 720 & -1036 & 917 & 0.642 \\
\hline \multirow{6}{*}{ 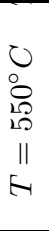 } & TT039_1.56.10-2_550 & \pm 0.39 & $1.56 .10^{-2}$ & 0 & 148500 & -614 & 558 & 0.026 \\
\hline & TT04_1.6.10-2_550 & \pm 0.4 & $1.6 .10^{-2}$ & 0 & 76500 & -641 & 590 & 0.021 \\
\hline & TT0425_1.7.10-2_550 & \pm 0.425 & $1.7 .10^{-2}$ & 0 & 44000 & -705 & 643 & 0.017 \\
\hline & TT0475_1.9.10-2_550 & \pm 0.475 & $1.9 .10^{-2}$ & 0 & 8400 & -753 & 697 & 0.069 \\
\hline & TT05_2.10-2_550 & \pm 0.5 & $2.10^{-2}$ & 0 & 9000 & -741 & 671 & 0.093 \\
\hline & TT06_2.4.10-2_550 & \pm 0.6 & $2.4 .10^{-2}$ & 0 & 3700 & -790 & 738 & 0.21 \\
\hline \multirow{5}{*}{$\begin{array}{l}0 \\
0 \\
8 \\
0 \\
10 \\
11\end{array}$} & FTRT1.1_10-3_78_560 & +1.1 & $10^{-3}$ & 78 & 1530 & -710 & 592 & 0.189 \\
\hline & FTRT1.2_10-3_76_560 & +1.2 & $10^{-3}$ & 76 & 1000 & -723 & 624 & 0.275 \\
\hline & FTRT1.35_10-3_73_560 & +1.35 & $10^{-3}$ & 73 & 820 & -706 & 627 & 0.436 \\
\hline & FTRT1.5_10-3_70_560 & +1.5 & $10^{-3}$ & 70 & 560 & -760 & 679 & 0.509 \\
\hline & FTRT1.8_10-3_64_560 & +1.8 & $10^{-3}$ & 64 & 445 & -745 & 680 & 0.812 \\
\hline \multirow{6}{*}{$\begin{array}{l}\circlearrowright \\
\circ \\
8 \\
0 \\
\| \\
\text { H. }\end{array}$} & TT034_1.36.10-2_600 & \pm 0.34 & $1.36 .10^{-2}$ & 0 & 32000 & -514 & 517 & 0.013 \\
\hline & TT035_1.4.10-2_600 & \pm 0.35 & $1.4 .10^{-2}$ & 0 & 19000 & -526 & 512 & 0.029 \\
\hline & TT0375_1.5.10-2_600 & \pm 0.375 & $1.5 .10^{-2}$ & 0 & 16800 & -571 & 557 & 0.021 \\
\hline & TT04_1.6.10-2_600 & \pm 0.4 & $1.6 .10^{-2}$ & 0 & 17000 & -549 & 514 & 0.038 \\
\hline & TT045_1.8.10-2_600 & \pm 0.45 & $1.8 .10^{-2}$ & 0 & 6500 & -617 & 613 & 0.103 \\
\hline & TT05_2.10-2_600 & \pm 0.5 & $2.10^{-2}$ & 0 & 4800 & -604 & 591 & 0.161 \\
\hline
\end{tabular}

Table 5: Test conditions and results $\left(\mathrm{T}=520^{\circ} \mathrm{C}\right)^{40}$

\begin{tabular}{|c|c|c|c|c|c|c|c|c|}
\hline & Specimen & $\Delta \varepsilon[\%]$ & $\dot{\varepsilon}\left[s^{-1}\right]$ & $t_{\text {dwell }[\mathrm{s}]}$ & $N_{R}$ [cycles] & $\sigma_{m}$ & $\sigma_{M}[\mathrm{MPa}]$ & $\Delta \varepsilon_{p}[\%]$ \\
\hline \multirow{13}{*}{ 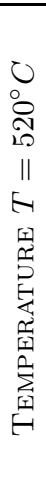 } & TT06_10-2_520 & \pm 0.6 & $10^{-2}$ & 0 & 3416 & -922 & 865 & 0.148 \\
\hline & $\begin{array}{lll}\text { TT06 } & 6.10-4 & 520\end{array}$ & \pm 0.6 & $6.10^{-4}$ & 0 & 3354 & -869 & 813 & 0.21 \\
\hline & $\begin{array}{lll}\text { TT075 } & 10-3 & 520\end{array}$ & \pm 0.75 & $10^{-3}$ & 0 & 1189 & $\overline{-926}$ & 873 & 0.441 \\
\hline & TT09 $10-2 \quad 520$ & \pm 0.9 & $10^{-2}$ & 0 & 878 & -991 & 940 & 0.663 \\
\hline & TT09_10-3_520 & \pm 0.9 & $10^{-3}$ & 0 & 565 & -986 & 939 & 0.667 \\
\hline & TRT06_10-3_20_520 & \pm 0.6 & $10^{-3}$ & 20 & 2326 & -935 & 789 & 0.183 \\
\hline & TRT075_10-3_20_520 & \pm 0.75 & $10^{-3}$ & 20 & 974 & -978 & 872 & 0.411 \\
\hline & TRT09_10-3_20_520 & \pm 0.9 & $10^{-3}$ & 20 & 544 & -946 & 861 & 0.73 \\
\hline & CRT06_10-3_20_520 & \pm 0.6 & $10^{-3}$ & 20 & 1326 & -763 & 873 & 0.201 \\
\hline & CRT075_10-3_20_520 & \pm 0.75 & $10^{-3}$ & 20 & 708 & -919 & 923 & 0.417 \\
\hline & CRT09_10-3_20_520 & \pm 0.9 & $10^{-3}$ & 20 & 470 & -912 & 910 & 0.721 \\
\hline & CRT06_10-3_60_520 & \pm 0.6 & $10^{-3}$ & 60 & $\overline{977}$ & -822 & 852 & 0.249 \\
\hline & CRT09_10-3_60_520 & \pm 0.9 & $10^{-3}$ & 60 & 528 & -933 & 939 & 0.7 \\
\hline
\end{tabular}




\section{Fracture mechanisms}

Qualitative SEM (Scanning Electron Microscope) examinations were performed (fracture surfaces and longitudinal observations) in order to investigate the fracture mechanisms. Fatigue specimens were chosen in order to enhance either the fatigue damage (transgranular) and either the creep damage (intergranular) mechanisms. So, post mortem observations were carried out on samples FTRT, CRT and TRT. Test conditions seem to be adequate to develop both kinds of damage mechanisms depending on strain rate and temperature. ${ }^{10}$

Recent investigations performed on martensitic steels have shown three damage mechanisms: ${ }^{41}$

- transgranular damage

- intergranular damage

- damage due to environment
Intergranular damage was never observed on AISI H11 steel, 12,42 indeed, all the observations have shown a transgranular propagation of cracks (damage due to the fatigue process) perpendicular to the loading direction. Our observations confirm the previous results (figure 9a) whatever the test conditions. Some crack initiations within the specimen were also observed (figure 9b). Two kinds of cracks can be seen on such steel, ${ }^{42}$ thin cracks that seem to propagate along the martensitic lath boundaries and very wide cracks not influenced by the microstructure. Fatigue striation zones appear on the fracture surfaces (figure 9c); they depend on the test strain range and are very difficult to observe for the small strain amplitudes. On the contrary, striation spacing measurements allow to determine the crack propagation history for the high strain amplitudes. ${ }^{42}$

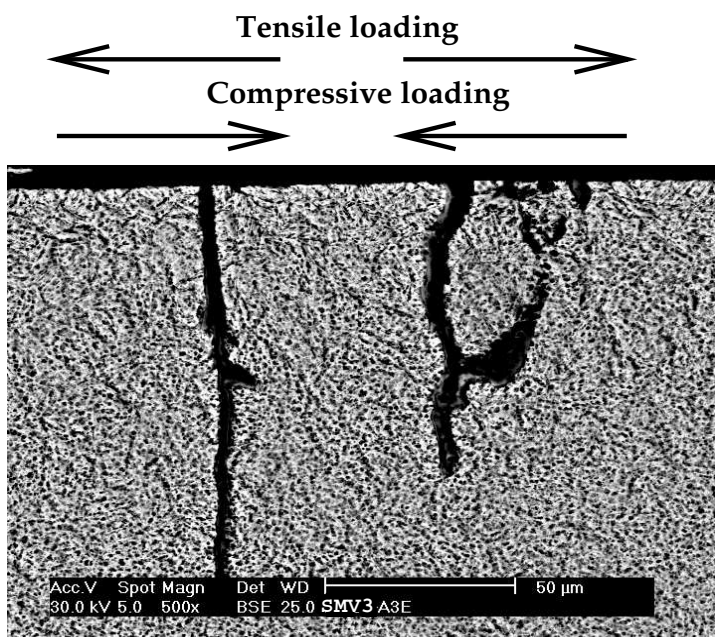

Fig. 9a: Transgranular crack propagation observed on the sample FTRT1.5_10-3_70_560

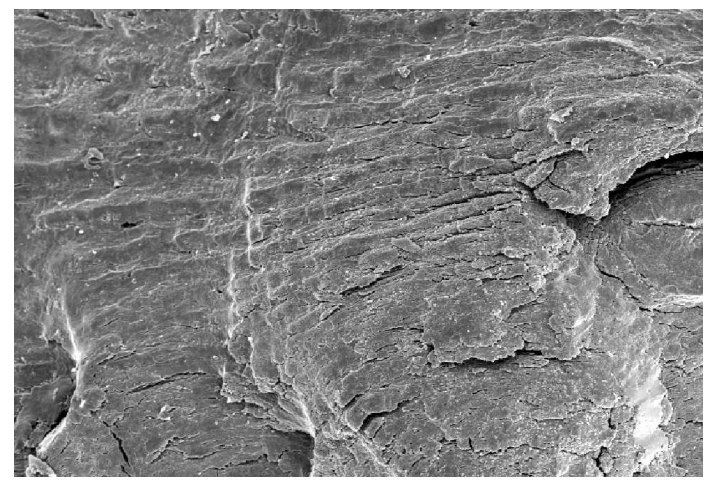

Fig. 9c: Fatigue striation zone observed on the fracture surface for the sample FTRT1.8_10-3_64_560

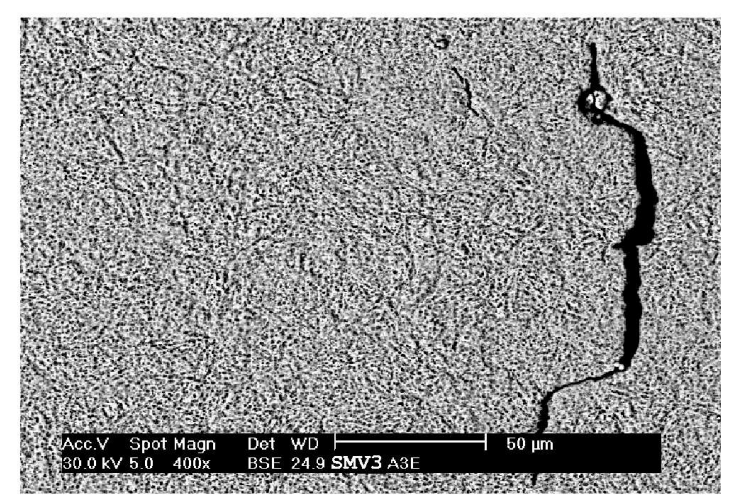

Fig. 9b: Internal crack initiation observed on the sample FTRT1.5_10-3_70_560 (longitudinal section)

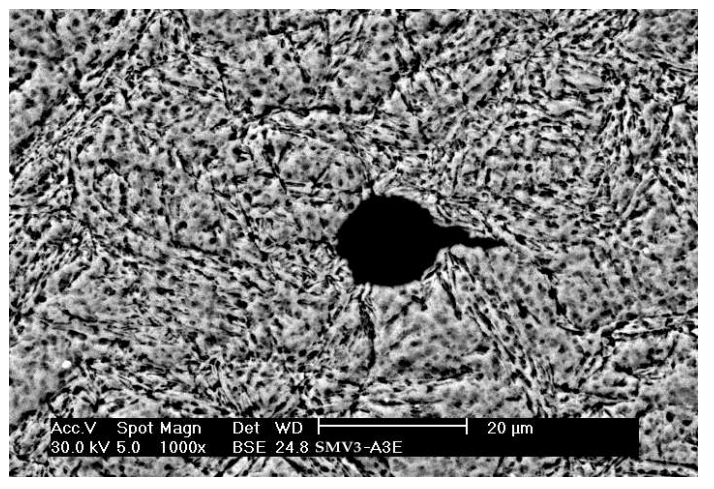

Fig. 9d: Crack initiation on a non metallic inclusion observed on FTRT1.5_10-3_70_560 test specimen 


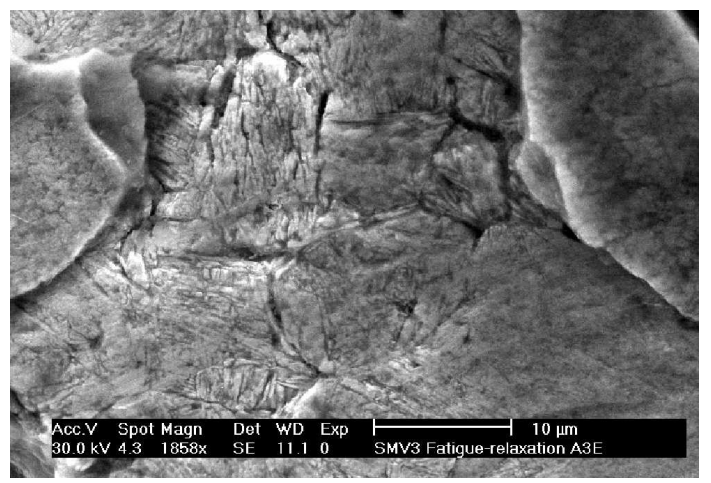

Fig. 9e: Grain decohesion near the fracture observed on sample FTRT1.5 $10-3 \quad 70 \quad 560$

Crack initiation mechanisms are more complex to determine. Indeed, the oxide layer often makes difficult microscopic observations. So, it is very hard to differentiate the oxide intrusion from the thin crack initiation. However, three initiation mechanisms were observed: ${ }^{12}$

- Non metallic inclusion NMI (figure 9d)

- Lath boundaries

- Grain boundaries of the initial austenitic microstructure

These mechanisms were quantified for several temperature conditions. So, NMI and lath boundary initiation proportion decreases with increasing test temperature whereas the grain boundary initiation increases. Thus, this mechanism is negligible for the temperature below $400^{\circ} \mathrm{C}$ and reaches a proportion of $30 \%$ at $500^{\circ} \mathrm{C}, 65 \%$ at $550^{\circ} \mathrm{C}$ and $90 \%$ at $600^{\circ} \mathrm{C}^{12}$

In this investigation, some examinations around the fracture surface allow to exhibit the martensitic microstructure, as the oxide layer is spread away during the sample rupture. So, the microstructure observation near the crack initiation becomes possible without any Nital etching (figure 9e). Thus, the martensite lathes which are located within the grains of the initial austenitic structure can be observed (figure 9e); a grain decohesion seems to appear and an intergranular crack initiation could be suggested (figures 9e and 9f). Crack growth observed on AISI H11 steel are transgranular whatever the test conditions, selected to be close to in-service tool conditions. Additional SEM examinations seem necessary to investigate crack initiation mechanisms. Indeed, they may be transgranular but may also occur on the austenitic grain boundaries. Lapovok et $\mathrm{al}^{43}$ have carried out some investigations on the AISI H13 steel and have clearly observed an intergranular crack

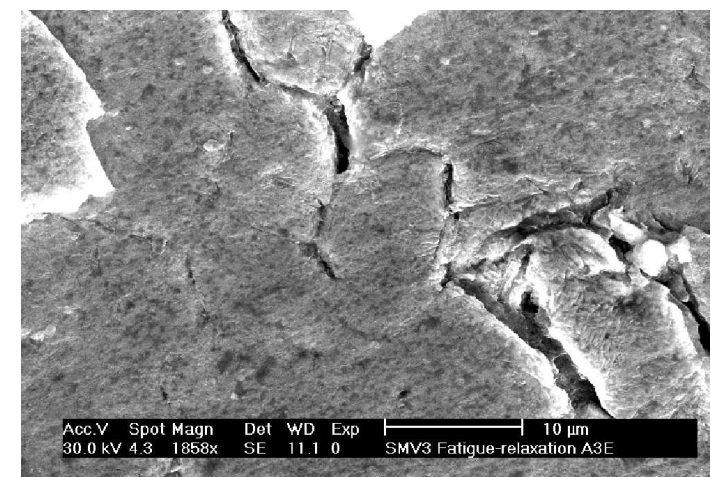

Fig. 9f: Grain boundary crack initiation near the fracture of the specimen FTRT1.5_10-3_70_560

initiation followed by a mainly transgranular propagation. ${ }^{43,44}$

\section{LIFETIME MODEL}

Fatigue resistance is determined by the material lifetime through the number of cycles to failure. In this kind of formulations, stress is the critical value and can be represented by Woehler curve (maximal stress versus the number of cycles to failure). It can be divided into three different domains:

- Low cycle fatigue domain (domain 1) for very high stress amplitudes and a number of cycles to failure until $5.10^{4}$ cycles.

- Limited high cycle fatigue domain (domain 2) for lower stress amplitudes and a number of cycles to failure between $5.10^{4}$ and $5.10^{6}$ cycles.

- Unlimited high cycle fatigue domain (domain 3) for very low stress amplitude and a number of cycles to failure between $10^{7}$ and $10^{9}$ cycles.

The present investigation is relative to the first and the beginning of the second domain. Usually, the number of cycles before an irreversible damage of the hot forming tools is lower than $10^{5}$ cycles for AISI H11 and L6 steels.

The continuous cyclic softening of the martensitic steels until rupture does not allow to define a stabilized cycle to determine the Woehler curves, so a pseudo stabilized cycle is selected at mid-life. Indeed, a very small continuous cyclic softening occurs at this stage.

Non linear continuum damage model includes two components.

- Fatigue damage can be expressed with the number of cycles $d D=f\left(\sigma_{M}, \bar{\sigma}, D\right) d N$. 
- Creep damage describes the time dependent mechanisms and is formulated with time. Its calculation is done by integrating an equivalent mean stress over a cycle. No significant creep rupture mechanisms have been observed during fracture analysis. Then, it is assumed to be negligible in comparison with the fatigue damage and the creep model component is not considered in the following.

\section{Fatigue damage}

If only fatigue damage component is activated, the law takes into account the characteristic values of a cycle: maximal stress $\sigma_{M}$ or stress amplitude $\Delta \sigma / 2$ and mean stress $\bar{\sigma}$. Several evolution laws were formulated to describe the damage variation from 0 to $1 .^{31}$

However, experimental damage investigations performed on most of materials have shown a damage rate equals to zero at the very beginning of the test and close to infinite near the rupture. Therefore, the following form ${ }^{30,33,34}$ was usually adopted for the damage law:

$$
\begin{aligned}
& d D=\left(1-(1-D)^{\beta+1}\right)^{\alpha}\left(\frac{\frac{\Delta \sigma}{2 M(\bar{\sigma})}}{(1-D)}\right)^{\beta} d N \\
& \alpha=\alpha\left(\sigma_{M}, \bar{\sigma}\right) \\
& M(\bar{\sigma})=M_{0}(1-b \bar{\sigma})
\end{aligned}
$$

Coefficient $\alpha$ describes the fatigue damage cumulation which can be considered linear if $\alpha$ is taken as a loading independent parameter or non linear if $\alpha$ is taken as a loading dependent parameter. ${ }^{17}$ In this last case, different expressions are available to define this coefficient. ${ }^{29}$
Most of them consider the fatigue limit and the maximal stress. Nowadays, the following form is used for most of materials:

$$
\alpha=1-a \frac{\left\langle\sigma_{M}-\sigma_{l}\right\rangle}{\left\langle\sigma_{u}-\sigma_{M}\right\rangle}
$$

with:

$$
\sigma_{l}=\bar{\sigma}+\sigma_{l_{0}}(1-b \bar{\sigma})
$$

If only fatigue damage occurs, integration of damage variable between 0 (virgin material) and 1 (macro crack initiation) provides the number of cycles to failure of the representative volume element. Depending on the phenomena considered, different expressions can be obtained:

$$
N_{R}=\frac{1}{1-\alpha} \frac{1}{1+\beta}\left(\frac{\Delta \sigma}{2 M}\right)^{-\beta}
$$

if $\alpha$ is considered as a loading independent parameter, and:

$$
N_{R}=\frac{1}{a(\beta+1)} \frac{\left\langle\sigma_{u}-\sigma_{M}\right\rangle}{\left\langle\sigma_{M}-\sigma_{l}\right\rangle}\left(\frac{\Delta \sigma}{2 M}\right)^{-\beta}
$$

if $\alpha$ is considered as a loading dependent parameter.

Moreover, fatigue damage evolution can be formulated with respect to the ratio number of cycles versus number of cycles to failure:

$$
D=1-\left(1-\left(\frac{N}{N_{R}}\right)^{\frac{1}{1-\alpha}}\right)^{\frac{1}{\beta+1}}
$$
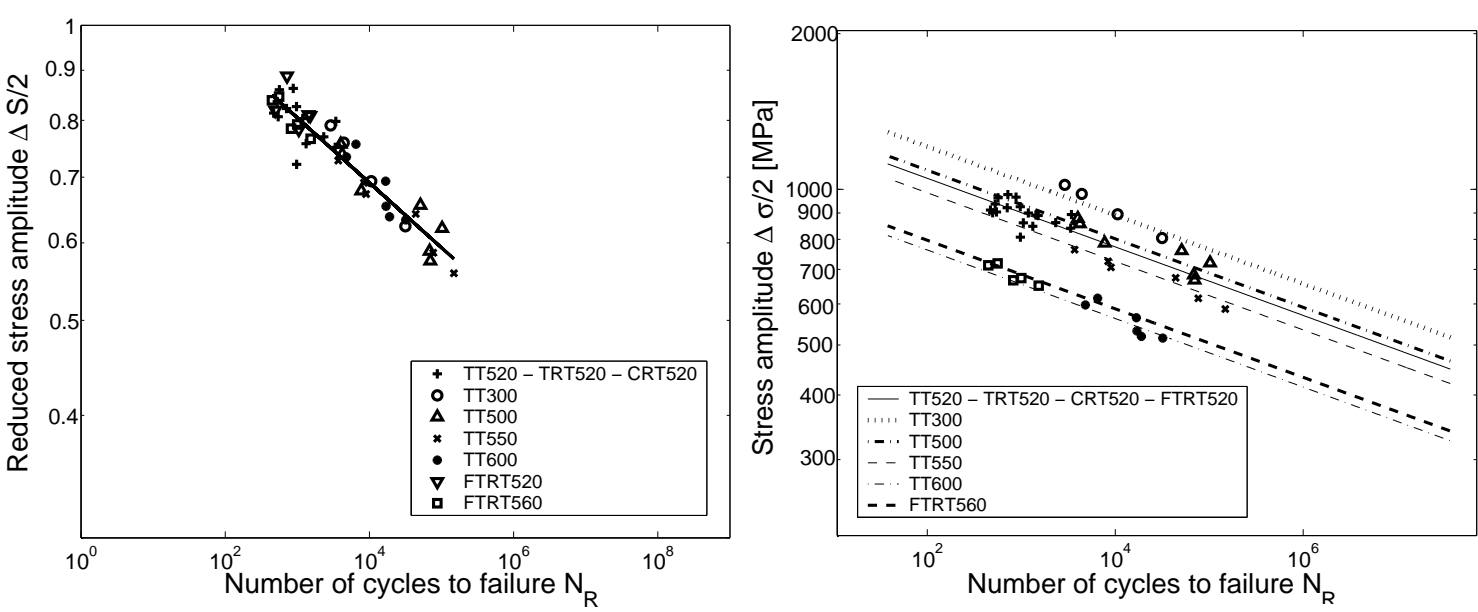

Fig. 10a: Woehler curves including all the experimental data Fig. 10b: Woehler diagram for the different temperature base used for the identification process. 


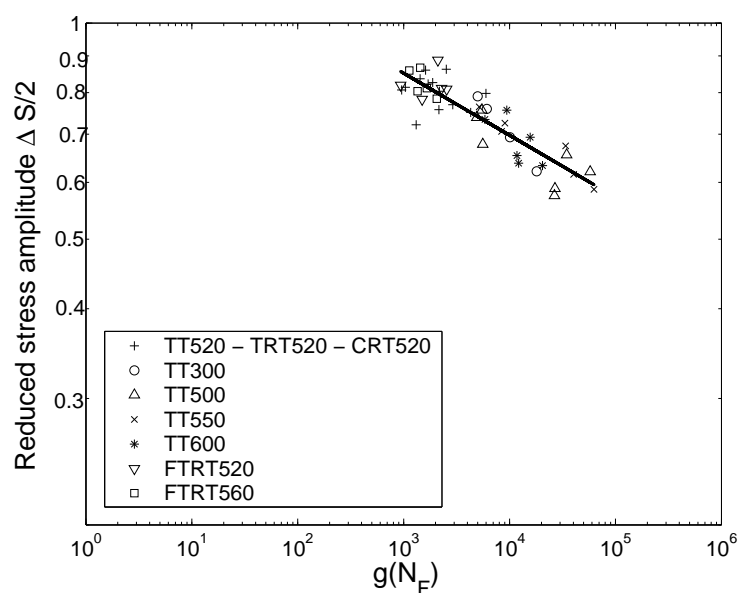

Fig. 10c: Reduced Woehler curve including all the experimental data base used for the identification process.

In addition with the mean stress effect and the non linear cumulation rule, such a model is accurate when the temperature evolves within the mechanical cycle (Thermal or thermomechanical fatigue). Then, the reduced stress notion $S=\frac{\sigma}{\sigma_{u}}$ obtained by dividing the mechanical parameters by the ultimate stress, is adopted.

Thus, previous equations can be written as:

$$
\begin{aligned}
& d D=\left(1-(1-D)^{\beta+1}\right)^{\alpha}\left(\frac{\frac{\Delta S}{2 M}}{\frac{(1-D)}{\sigma u}}\right)^{\beta} d N \\
& \alpha=\alpha\left(\sigma_{M}\right) ; M=M(\bar{\sigma})=M_{0}(1-b \bar{\sigma})
\end{aligned}
$$

And the number of cycles to failure as:

$$
N_{R}=\frac{1}{1-\alpha} \frac{1}{1+\beta}\left(\frac{\Delta S / 2}{M / \sigma_{u}}\right)^{-\beta}
$$

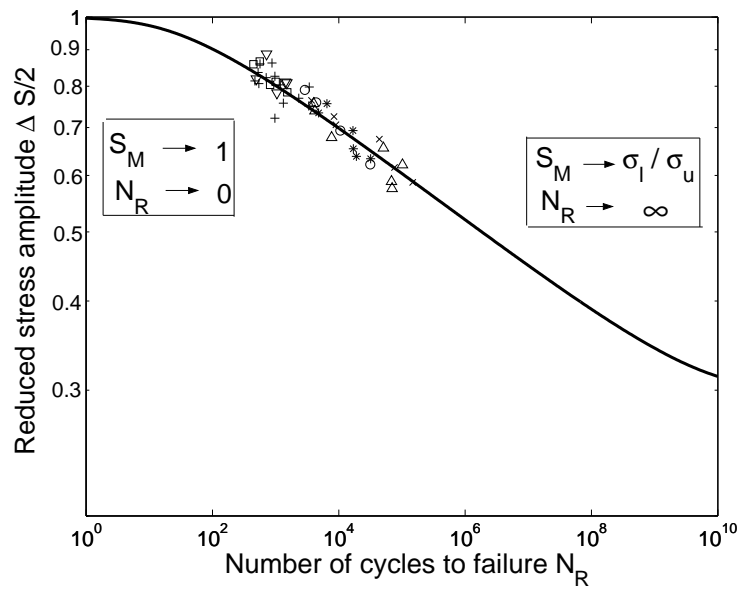

Fig. 11a: Normalized Woehler diagram including all the Fig. 11b: Woehler diagram for the different temperature fatigue data base.

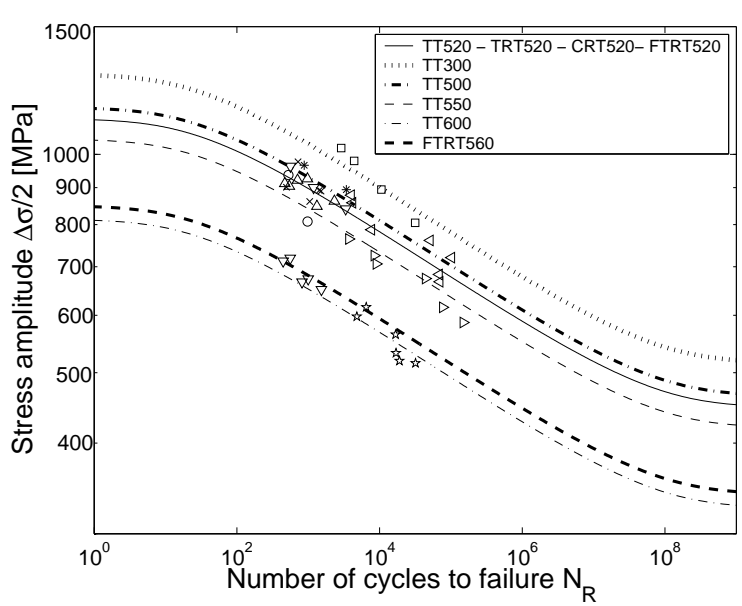

Using relation 2 , the equation becomes:

$$
N_{R}=\frac{1}{a(\beta+1)} \frac{\left\langle 1-S_{M}\right\rangle}{\left\langle S_{M}-\sigma_{l} / \sigma_{u}\right\rangle}\left(\frac{\Delta S / 2}{M / \sigma_{u}}\right)^{-\beta}
$$

For symmetrical cycles, $\bar{\sigma}=0$, the mean stress influence on the lifetimes is not considered anymore and $M=M_{0}$.

Relation 7 allows to plot the Woehler curve within the low cycle fatigue domain (Figures 10a and $10 \mathrm{~b}$ ), whereas relation 8 is able to reproduce the two limits of the Woehler curve, the ultimate stress when rupture occurs in a quarter of cycle and fatigue limit for an infinite number of cycles to failure (Figures 11a and 11b). levels considered. 


\section{Fatigue damage parameter identification}

Model parameters are determined by plotting the Woehler curves in a bilogarithmic diagram as shown in figure 10a. Thus, only one set of coefficients was determined for all the temperature levels. Two possibilities are considered:

- $\alpha$ as a loading independent parameter.

In this case, equation 7 is considered and:

$$
\begin{aligned}
& \log \left(\frac{\Delta S}{2}\right)=\frac{1}{\beta} \log \left(\frac{\left(\frac{M}{\sigma_{u}}\right)^{\beta}}{(1-\alpha)(1+\beta)}\right) \\
& -\frac{1}{\beta} \log \left(N_{R}\right)
\end{aligned}
$$

Slope and intersection of the straight line with Y-axis (see figure 10a) allow to identify $\beta$ and $Y_{0}=\frac{1}{\beta} \log \left(\frac{\left(\frac{M}{\sigma_{u}}\right)^{\beta}}{(1-\alpha)(1+\beta)}\right)$.

So, for all the temperature levels, only two coefficients have to be identified, $\beta$ and $C_{M}=(1-\alpha)\left(\frac{M}{\sigma_{u}}\right)^{-\beta}=\frac{e^{-\beta Y_{0}}}{1+\beta}$.

Figure 10a presents Woehler master curve of the AISI H11 steel. As expected, all the test results are on a same straight line whatever the test conditions (temperature, strain rates, dwell times) confirming that only a fatigue damage occurs. So, it is concluded that, for the test conditions considered close to those applied in the hot forming processes, AISI H11 steel is not affected by creep damage but only by fatigue damage. These results are in a good agreement with the SEM observations. ${ }^{12,42}$ Figure $10 \mathrm{~b}$ shows Woehler diagram provided for different temperature levels.

Identification results from figure $10 \mathrm{a}$ are reported in table 6 .

Finally, the number of cycles to failure can be calculated as:

$$
N_{R}=e^{\beta Y_{0}}\left(\frac{\Delta S}{2}\right)^{-\beta} .
$$

- $\alpha$ as a loading dependent parameter.

In this case, equations 2 and 8 are considered, and:

$$
\begin{gathered}
\log \left(\frac{\Delta S}{2}\right)=\frac{1}{\beta} \log \left(\frac{\left(\frac{M}{\sigma_{u}}\right)^{\beta}}{a(1+\beta)}\right) \\
-\frac{1}{\beta} \log \left(\frac{\left\langle S_{M}-\frac{\sigma_{l}}{\sigma_{u}}\right\rangle}{\left\langle 1-S_{M}\right\rangle} N_{R}\right) .
\end{gathered}
$$

As previously, parameters $\beta$ and $Y_{0}$ can be determined from the bilogarithmic diagram (see figure 11a):

$$
\frac{\Delta S}{2}=f\left(\frac{\left\langle S_{M}-\frac{\sigma_{l}}{\sigma_{u}}\right\rangle}{\left\langle 1-S_{M}\right\rangle} N_{R}\right)
$$

with:

$$
\begin{aligned}
& Y_{0}=\frac{1}{\beta} \log \left(\frac{\left(\frac{M}{\sigma_{u}}\right)^{\beta}}{a(1+\beta)}\right) \\
& \text { and: } \\
& g\left(N_{R}\right)=\frac{\left\langle S_{M}-\frac{\sigma_{l}}{\sigma_{u}}\right\rangle}{\left\langle 1-S_{M}\right\rangle} N_{R}
\end{aligned}
$$

A constant value is assumed for the fatigue limit ratio over ultimate stress: $\frac{\sigma_{l}}{\sigma u}=0.3$.

As previously, for all the temperature levels, only two coefficients have to be identified: $\beta$ and $C_{M}=a\left(\frac{M}{\sigma_{u}}\right)^{-\beta}=\frac{e^{\beta Y_{0}}}{1+\beta}$.

Finally, the number of cycles to failure is written as follows:

$$
N_{R}=\frac{\left\langle 1-S_{M}\right\rangle}{\left\langle S_{M}-\frac{\sigma_{l}}{\sigma_{u}}\right\rangle} e^{\beta Y_{0}}\left(\frac{\Delta S}{2}\right)^{-\beta}
$$

In this case, identified values obtained are given in table 6 .

Figures 11a and 11b show on the one hand reduced Woehler curve given by equation 13 and on the other hand Woehler curves by temperature levels.

If necessary, the model could be modified in order to take into account the mean stress effect (non symmetrical loadings) through the fatigue limit $\sigma_{l}$ which increases with the mean stress and the parameter $M$.

\section{- Results}

Figures $12 \mathrm{a}$ and $12 \mathrm{~b}$ compare experimental and calculated lifetimes in the cases where $\alpha$ is taken as loading dependent and loading independent parameter. Results with a scattering factor 2 on lifetimes are usually accepted in fatigue. Table 7 compares experimental and calculated number of cycles to failure for all the fatigue data base. 
Table 6: Results provided by the identification process

\begin{tabular}{lcc}
\hline & $\beta$ & $C_{M}$ \\
\hline$\alpha$ as a loading independent parameter & 15.1 & $1.6510^{-3}$ \\
\hline$\alpha$ as a loading dependent parameter & 12 & $4.3110^{-4}$ \\
\hline
\end{tabular}
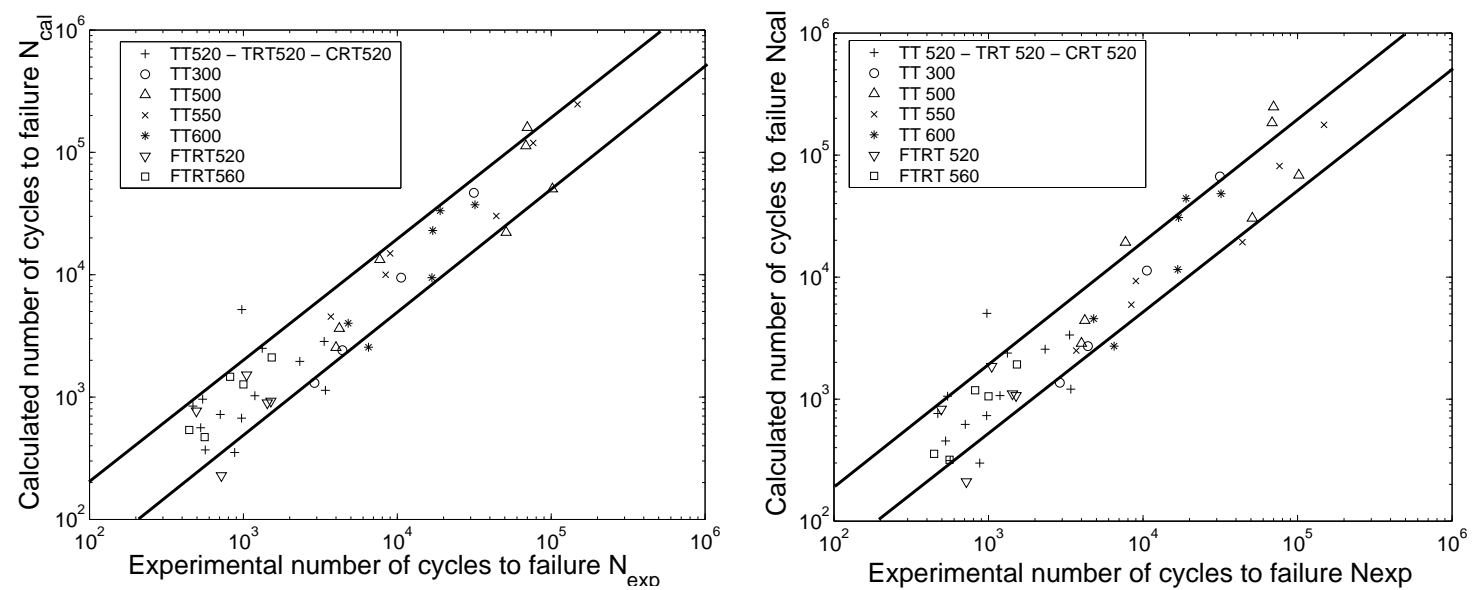

Fig. 12a: Comparison between experimental and calculated Fig. 12b: Comparison between experimental and calculated number of cycles to failure for $\alpha$ taken as independent loading number of cycles to failure for $\alpha$ taken as dependent loading parameter. parameter.

\section{Test validation}

This part is devoted to a first validation of the lifetime model. For that purpose, low cycle fatigue and thermomechanical fatigue tests performed on AISI H11 in a previous investigation by Oudin ${ }^{42}$ were selected. Validation stage consists in comparing experimental lifetimes with those provided by the lifetime model. Compressive out of phase thermomechanical tests between temperatures $T_{\min }$ et $T_{\max }$ are considered. The mid-life parameters are normalized by the ultimate stress for the corresponding temperature, so, all the reduced values remains between 0 et 1 during the thermomechanical cycle.

$$
\begin{aligned}
S_{M} & =\frac{\sigma_{M}}{\sigma_{u}\left(T_{\min }\right)} ; \quad S_{m}=\frac{\sigma_{m}}{\sigma_{u}\left(T_{\max }\right)} ; \\
\frac{\Delta S}{2} & =\frac{1}{2}\left(S_{M}-S_{m}\right)
\end{aligned}
$$

Test conditions, number of cycles to failure and mid-life parameters ${ }^{42}$ are reported in table 8.

In order to be able to apply the lifetime model, the stress-strain responses of the material under the test conditions of table 8 have to be calculated. Previous investigations ${ }^{2-4,40}$ have allowed to identify phenomenological behavior models under non isothermal conditions and well adapted to martensitic hot work tool steels. Such constitutive viscoplastic behavior models consider two kinematic components in order to describe the stress-strain reponse and two isotropic components to reproduce the cyclic softening of AISI H11 steel. Moreover, one of the kinematic component includes a strain memory effect They were used to assess mid-life parameters necessary for the lifetime model implementation. Figures $13 \mathrm{a}$ and $13 \mathrm{~b}$ exhibit the behavior model responses. On the one hand, calculated compressive out of phase cycles between $200^{\circ} \mathrm{C}$ and $550^{\circ} \mathrm{C}$ are presented, on the other hand, figure $13 \mathrm{~b}$ shows the different corresponding cyclic softening curves. ${ }^{3,40}$ The different thermomechanical test conditions are described in table 8 .

The mean stress effect should be considered for the thermomechanical fatigue tests, however, this effect is assumed to be negligible because of the very short lifetimes considered. Calculated lifetimes are plotted on the previously determined non linear master curve (figure 14a). The good agreement gives a preliminary validation of the lifetime model as shown in figure 14b where predictions are compared with test results. 

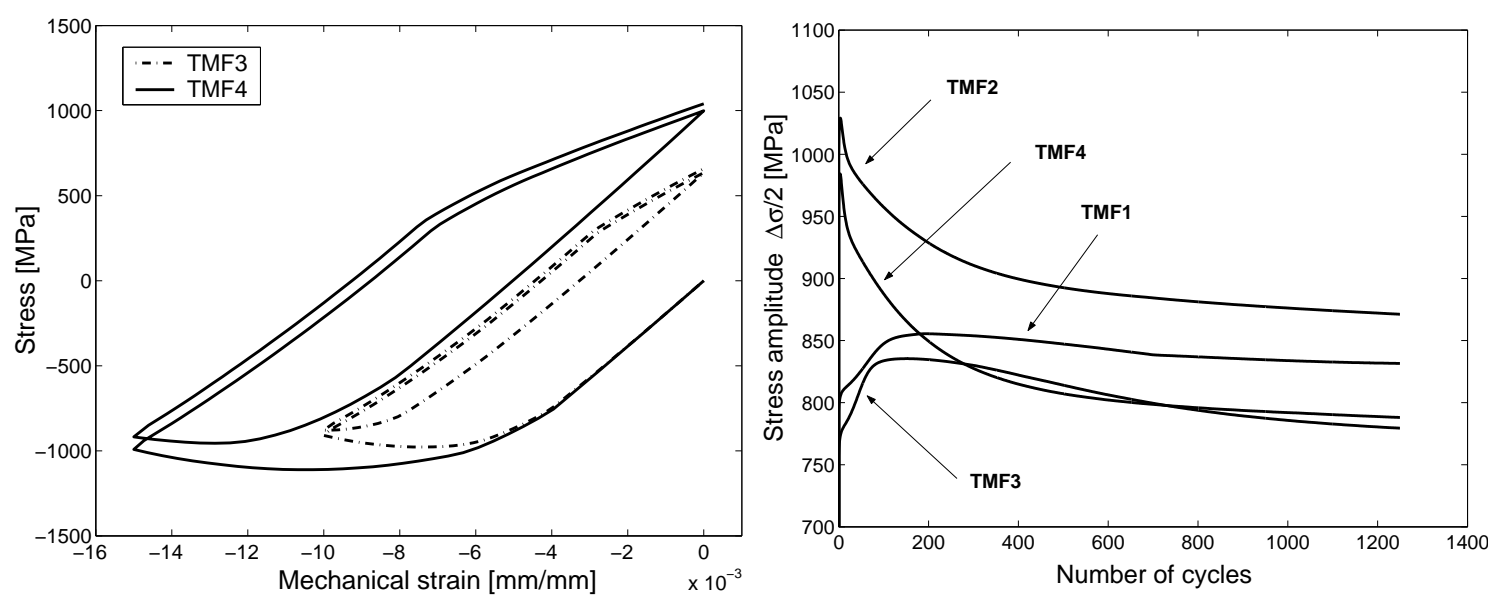

Fig. 13a: Mechanical strain-stress responses of out of phase Fig. 13b: Cyclic softening of out of phase thermomechanical thermomechanical cycles provided by a behavior model ${ }^{40}$
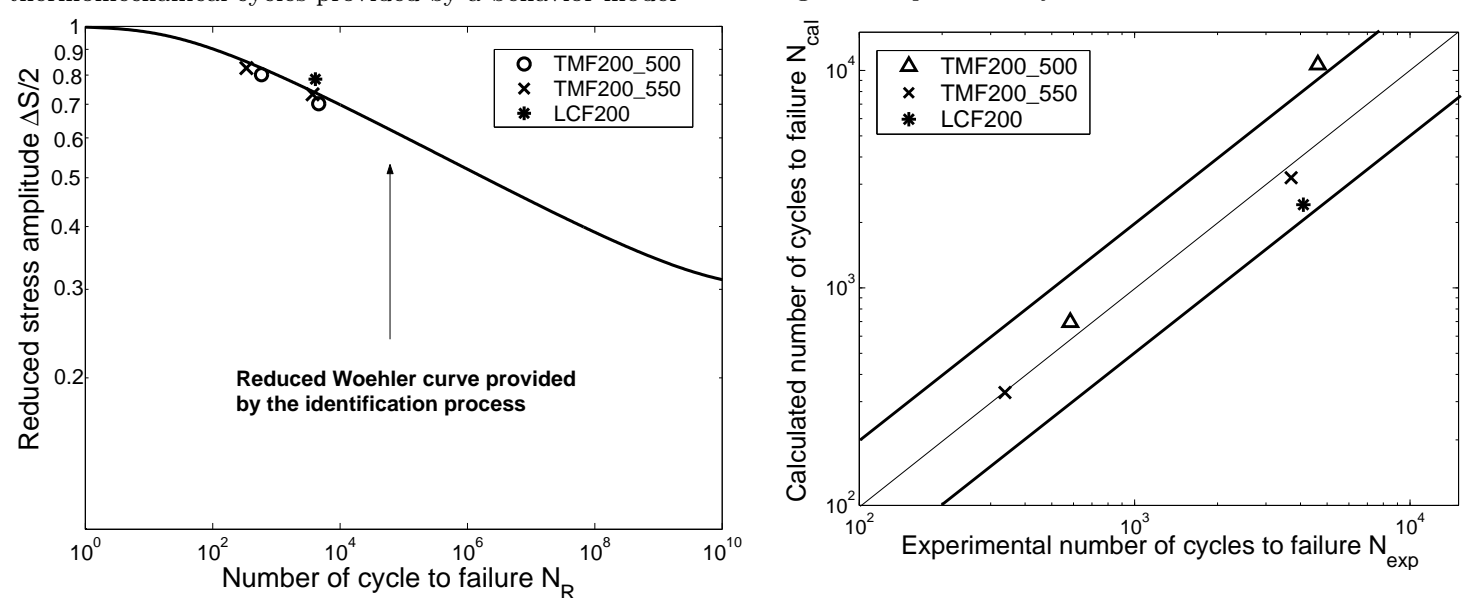

Fig. 14b: Comparison between experimental and calculated Fig. 14a: Reduced Woehler curves with the validation ther- number of cycles to failure for the Thermo-mechanical fatigue momechanical fatigue tests.

tests. 
Table 7: Comparison between experimental and calculated number of cycles to failure.

\begin{tabular}{|c|c|c|c|c|}
\hline & Specimen & $N_{\text {Rexp }}$ & $N_{\text {Rcal }}{ }^{2}$ & $N_{\text {Rcal }}{ }^{3}$ \\
\hline \multirow{4}{*}{$\begin{array}{l}\circlearrowright \\
\circ \\
\stackrel{0}{\circ} \\
\end{array}$} & TT0425-1.7.10-2-300 & 31500 & 46683 & 64879 \\
\hline & TT05-2.10-2-300 & 10600 & 9466 & 11340 \\
\hline & TT06-2.4.10-2-300 & 4400 & 2413 & 2753 \\
\hline & ТT07-2.8.10-2-300 & 2900 & 1305 & 1379 \\
\hline \multirow{7}{*}{$\begin{array}{l}0 \\
0 \\
8 \\
8 \\
11 \\
\| \\
\text { H }\end{array}$} & TT045-1.8.10-2-500 & 68500 & 113078 & 173831 \\
\hline & TT045-1.8.10-2-500 & 70000 & 159948 & 230228 \\
\hline & TT046-1.84.10-2-500 & 102000 & 50324 & 66560 \\
\hline & TT0475-1.9.10-2-500 & 51000 & 22166 & 30150 \\
\hline & TT05-2.10-2-500 & 7709 & 13305 & 19263 \\
\hline & TT06-2.4.10-2-500 & 4200 & 3641 & 4467 \\
\hline & TT06-2.4.10-2-500 & 4000 & 2541 & 2900 \\
\hline \multirow{18}{*}{ 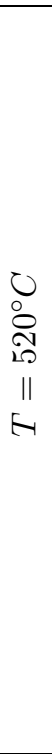 } & TT06-10-2-520 & 3416 & 1346 & 1221 \\
\hline & TT06-6.10-4-520 & 3354 & 2851 & 3388 \\
\hline & TT075-10-3-520 & 1189 & 1026 & 1080 \\
\hline & TT09-10-2-520 & 878 & 352 & 300 \\
\hline & TT09-10-3-520 & 565 & 370 & 315 \\
\hline & TRT06-10-3-20-520 & 2326 & 1958 & 2598 \\
\hline & TRT075-10-3-20-520 & 974 & 671 & 739 \\
\hline & TRT09-10-3-20-520 & 544 & 961 & 1068 \\
\hline & CRT06-10-3-20-520 & 1326 & 2502 & 2414 \\
\hline & CRT075-10-3-20-520 & 708 & 720 & 627 \\
\hline & CRT09-10-3-20-520 & 470 & 844 & 770 \\
\hline & CRT06-10-3-60-520 & 977 & 5195 & 5089 \\
\hline & CRT09-10-3-60-520 & 528 & 561 & 459 \\
\hline & FTRT1.2-10-3-76-520 & 1510 & 925 & 1081 \\
\hline & FTRT1.35-10-3-73-520 & 1430 & 896 & 1116 \\
\hline & FTRT1.5-10-3-70-520 & 1050 & 1518 & 1876 \\
\hline & FTRT1.8-10-3-64-520 & 495 & 768 & 836 \\
\hline & FTRT1.8-10-3-64-520 & 720 & 227 & 211 \\
\hline \multirow{6}{*}{$\begin{array}{l}0 \\
0 \\
0 \\
10 \\
10 \\
\| 1 \\
\text { E- }\end{array}$} & TT039-1.56.10-2-550 & 148500 & 247190 & 166690 \\
\hline & TT04-1.6.10-2-550 & 76500 & 119297 & 78648 \\
\hline & TT0425-1.7.10-2-550 & 44000 & 30179 & 19315 \\
\hline & TT0475-1.9.10-2-550 & 8400 & 10009 & 5995 \\
\hline & TT05-2.10-2-550 & 9000 & 14932 & 9352 \\
\hline & TT06-2.4.10-2-550 & 3700 & 4551 & 2528 \\
\hline \multirow{5}{*}{$\begin{array}{l}0 \\
0 \\
0 \\
0 \\
11 \\
11 \\
\text { E. }\end{array}$} & FTRT11-10-3-78-560 & 1530 & 2106 & 1945 \\
\hline & FTRT12-10-3-76-560 & 1000 & 1267 & 1066 \\
\hline & FTRT135-10-3-73-560 & 820 & 1465 & 1194 \\
\hline & FTRT15-10-3-70-560 & 560 & 471 & 320 \\
\hline & FTRT18-10-3-64-560 & 445 & 538 & 359 \\
\hline \multirow{6}{*}{$\begin{array}{l}0 \\
0 \\
8 \\
8 \\
11 \\
-1\end{array}$} & TT034-1.36.10-2-600 & 32000 & 37323 & 47237 \\
\hline & TT035-1.4.10-2-600 & 19000 & 33373 & 43325 \\
\hline & TT0375-1.5.10-2-600 & 16800 & 9462 & 11592 \\
\hline & TT04-1.6.10-2-600 & 17000 & 22950 & 30441 \\
\hline & TT045-1.8.10-2-600 & 6500 & 2553 & 2751 \\
\hline & TT05-2.10-2-600 & 4800 & 4009 & 4604 \\
\hline
\end{tabular}

${ }^{2} \alpha$ as loading independent parameter

${ }^{3} \alpha$ as loading dependent parameter 
Table 8: LCF and TMF test conditions and results performed on AISI H11 steel according to Oudin ${ }^{42}$

\begin{tabular}{cccccccc}
\hline Specimen & Period $[\mathrm{s}]$ & $T_{\min }\left[{ }^{\circ} \mathrm{C}\right]$ & $T_{\max }\left[{ }^{\circ} \mathrm{C}\right]$ & $\Delta \varepsilon_{\text {mech }}[\%]$ & $\sigma_{M}$ & $\sigma_{m}$ & $N_{R}$ \\
\hline LCF & -- & 200 & 200 & 1.35 & 860 & -1250 & 4100 \\
\hline TMF1 & 190 & 200 & 500 & 1 & 900 & -850 & 4600 \\
\hline TMF2 & 190 & 200 & 500 & 1.5 & 1200 & -900 & 590 \\
\hline TMF3 & 226 & 200 & 550 & 1 & 1000 & -500 & 3700 \\
\hline TMF4 & 226 & 200 & 550 & 1.5 & 1250 & -750 & 325 \\
\hline
\end{tabular}

\section{CONCLUSION}

A continuum and phenomenological damage model was successfully identified on a martensitic hot work tool steel AISI H11. It is able to reproduce an important data base coming from different investigations ${ }^{3,12}$ and including a very broad range of working conditions in terms of strain rates, strain amplitudes, dwell times and temperature levels. The microstructural examinations confirm previous investigations performed on the AISI H11 steel where only a transgranular crack propagation occurs. These results were confirmed by the lifetime model which only needs a fatigue damage component to assess the lifetimes of all the data base. This component can be expressed with a linear or a non linear cumulative fatigue damage rule. Both of them have provided results in a good agreement with experiments with a scattering factor 2 on lifetimes. However, the non linear rule allows the description of all the Woehler curve domains and seems to be more suitable for fatigue lifetime prediction over a broad range of loading conditions. As a matter of fact, loadings resulting from the industrial processes like forging or die casting, induce a very important thermal component with a temperature evolution within mechanical cycles. That's why additional thermomechanical fatigue tests ${ }^{42}$ were considered in order to be compared with the model prediction. Results show the model capabilities and constitute a first validation stage.

\section{Acknowledgement:}

The authors gratefully acknowledge Fabrice Rossi for his help during the mechanical tests and Serge Tovar for the SEM examinations.

\section{REFERENCES}

1 Bernhart G., Moulinier G., Brucelle O. and Delagnes D. (1999) High temperature low cycle behaviour of martensitic forging tool steel, International Journal of Fatigue 21(2), 179-186.

2 Zhang Z., Delagnes D. and Bernhart G. (2002) Anisothermal cyclic plasticity modeling of marten- sitic steels, International Journal of Fatigue 243, 635 .

3 Velay V., Bernhart G. and Penazzi L. (2005) Cyclic behavior modeling of a tempered martensitic hot work tool steel, International Journal of Plasticity In Press, Corrected Proof.

4 Velay V., Bernhart G., Zhang Z. and Penazzi L. (2002) Cyclic behaviour modeling of martensitic hot work tool steel, in: High Temperature Fatigue, Paderborn (Germany), 64-75, ISBN 3-00-0092544.

5 Germain P. and Muller P. (1995) Introduction à la mécanique des milieux continus, Masson, $2^{\circ}$ édition.

6 Halphen B. and Nguyen Q. (1974) Plastic and viscoplastic materials with generalized potential, $\mathrm{Me}$ chanics research communication 1(1), 43-47.

7 Chaboche J. (1989) Constitutive equations for cyclic plasticity and cyclic viscoplasticity, International Journal of Plasticity 5, 247-302.

8 Arnold S. and Saleeb A. (1994) On the thermodynamic framework of generalized coupled thermoelastic-viscoplastic-damage modeling, International Journal of Plasticity 10(3), 263-278.

9 Fatemi A. and Yang L. (1998) Cumulative fatigue damage and life prediction theories: a survey of the state of the art for homogeneous materials, International Journal of Fatigue 20(1), 9-34.

10 Coffin L. (1977) Fatigue at high temperature, in: Fracture 1977, vol. 1, edited by W.C. ICF4, 263274.

11 Manson L. (1974) Fatigue at high temperature prediction and interpretation, Proc Inst Mech Engrs $\mathbf{1 8 8}(9)$.

12 Delagnes D. (1998) Isothermal fatigue behaviour and lifetime of a $5 \% \mathrm{Cr}$ hot work tool steel around the LCF-HCF transition, Ph.D. thesis, Ecole Nationale Supérieure des Mines de Paris, in french.

13 Delagnes D. (2001) Fatigue-relaxation de $3 \mathrm{nu}-$ ances d'aciers à outils pour travail à chaud, Rapport d'activité contrat cadre 2000-2001, Ecole des Mines d'Albi-Carmaux In French.

14 Meider M. and Walter C. (1999) Prediction of fatigue life of cold forging tools by $\mathrm{FE}$ simulation and comparison on applicability of different damage models, in: Tool Steels in the Next Century, $5^{\text {th }}$ International Conference on Tooling (Leoben), 687-697.

15 Glinka G., Shen G. and Plumtree A. (1995) A multiaxial fatigue strain energy density parameter related to the critical failure plane, Fatigue and Fracture of Engineering Materials and Structures 18(1), 37-46. 
16 Halford G. and Saltsman J. (1985) Strain range partitioning - a total strain range version, $N A S A$ Lewis Research Center Cleveland, Ohio.

17 Lemaître J. and Chaboche J. (1994) Mechanics of solid materials, Cambridge University Press.

18 Yeom J., Williams S. and Park N. (2002) Low cycle fatigue life prediction for waspaloy, Materials at High Temperatures 19(3), 153-161.

19 Lesne P. (1985) Amorçage et propagation de fissures sous gradients thermiques cycliques, $\mathrm{Ph} . \mathrm{D}$ thesis, Université des Sciences et Techniques de Lille.

20 Ostergren W. (1976) A damage function and associated failure equations for predicting hold time and frequency effects in elevated temperature, low cycle fatigue, Journal of testing and evaluation 4(5), 327-339.

21 Skelton R. (1981) Energy criterion for high temperature low cycle fatigue failure, Materials Science and Technology 7, 427 .

22 Martin D. (1961) An energy criterion for low cycle fatigue, Journal of Basic Engineering , 565-571.

23 Skelton R., Vilhelmsen T. and Webster G. (1998) Energy criteria and cumulative damage fatigue crack growth, International Journal of Fatigue 20(9), 641-649.

24 Charkaluk E., Bignonnet A., Constantinescu A and Dang Van K. (2002) Fatigue design of structures under thermomechanical loadings, Fatigue and Fracture of Engineering Materials and Structures 25, 1199-1206.

25 Charkaluk E. and Constantinescu A. (2000) An energetic approach in thermomechanical fatigue for silicon molybdenum cast iron, Materials at High Temperatures 17(3), 373-380.

26 Charkaluk E. (1999) Dimensionnement des structures à la fatigue thermomécanique, Ph.D. thesis, Ecole polytechnique, in French.

27 Bignonnet A. and Charkaluk E. (2001) Thermomechanical fatigue in the automotive industry, in Temperature-Fatigue interaction, $9^{\text {th }}$ International Spring Meeting (Paris), 351-362.

28 Verger L., Constantinescou A. and Charkaluk E. (2001) Thermomechanical fatigue design of aluminium components, in: Temperature-Fatigue Interaction, $9^{\text {th }}$ International Spring Meeting (Paris), 293-302.

29 Chaboche J. and Lesne P. (1988) A non linear continuous fatigue damage model, Fatigue and Fracture of Engineering Materials and Structures 11(1), 1-17.

30 Chaboche J., Kaczmarek H. and Raine P. (1980) Sur les effets d'interaction de l'écrouissage et de l'endommagement dans l'acier 316 1, La recherche aérospatiale , 177-196In French.
31 Chaboche J. (1974) Une loi différentielle d'endommagement de fatigue avec cumulation non linéaire, Revue Française de Mécanique, 50-51In French.

32 Lemaître J. and Chaboche J. (1978) Aspect phénoménologique de la rupture par endommagement, Journal de Mécanique Appliquée 2(3).

33 Gomez V. (2002) Etude en fatigue biaxiale à haute température d'alliages métalliques pour disques de turbomachines aéronautiques, Ph.D. thesis, Université Paul Sabatier Toulouse 3.

34 Nicouleau-Bourles E. (1999) Etude expérimentale du vieillissement d'un alliage d'aluminium. application aux culasses d'automobiles, Ph.D. thesis, Ecole Nationale Supérieure des Mines de Paris, in French.

35 Shi H., Niu L., Korn C. and Pluvinage G. (2000) High temperature fatigue behaviour of TZM molybdenum alloy under mechanical and thermomechanical cyclic loads, Journal of Nuclear Materials 278, 328-333.

36 Xiao Y. (2004) A multi-mechanism damage coupling model, International Journal of Plasticity 26, 1241-1250.

37 Cailletaud G. and Levaillant C. (1984) Creepfatigue interaction: what about initiation ?, $\mathrm{Nu}$ clear Engineering Design 83, 279-292.

38 Gallerneau F. (1995) Etude et modélisation de l'endommagement d'un superalliage monocristallin revêtu pour aube de turbine, Ph.D. thesis, Ecole Nationale Supérieure des Mines de Paris.

39 Lemaître J. and Plumtree A. (1979) Application of damage concepts to predict creep-fatigue failures, Journal of Engineering Materials and Technology 101, 284-292.

40 Velay V. (2003) Cyclic behavior modeling and lifetime assessment of martensitic hot work tool steels, Ph.D. thesis, Ecole Nationale Supérieure des Mines de Paris, in french.

41 Sjöström J. and Bergström J. (2002) Evaluation of the cyclic behaviour during high temperature fatigue of hot work tool steels, in: $6^{\text {th }}$ International Tooling Conference, Karlstad (Sweden), 603-615.

42 Oudin A. (2001) Thermo-mechanical fatigue of hot work tool steels, Ph.D. thesis, Ecole Nationale Supérieure des Mines de Paris, non-confidential version.

43 Lapovok R. (1995) A damage approach to fatigue fracture of tools in metal working processes, CSIRO, Division of Manufacturing Technology, Australia.

44 Lapovok R., Smirnov S. and Shveykin V. (1996) Ductility defined as critical local strain, First Australian Congress on Applied Mechanics 